\title{
The Berlin Declaration: building upon St Vincent
}

\author{
Anne-Marie Felton ${ }^{1} \cdot$ Sanjay Kalra ${ }^{2}$
}

Received: 27 February 2017 / Accepted: 2 March 2017 / Published online: 26 March 2017

(C) Springer-Verlag Berlin Heidelberg 2017

Keywords Advocacy · Diabetes · Early action · Europe · Prevention of diabetes · Type 2 diabetes

\section{Abbreviation \\ UN United Nations}

To the Editor: Few events have had as important a bearing on diabetes care globally as did a meeting in a tiny Alpine village, St Vincent (Aosta Valley), 28 years ago. The St Vincent Declaration [1], released in the Italian village that gave it its name, heralded a revolutionary thought process and stimulated pioneering action to improve healthcare. Involving all of Europe, it brought people with diabetes, healthcare professionals and government representatives to the same table. It encouraged collaboration amongst governments, healthcare professionals and individuals with diabetes, so as to improve diabetes care and its outcomes. The Declaration influenced and encouraged national governments and relevant non-governmental organisations (NGOs) to establish their own declarations and commitments.

St Vincent laid down targets, some subjective, others objective, to be aimed at in order to achieve optimal diabetes care. These included the creation of programmes to: (1) detect and control diabetes and its complications; (2) raise awareness

Sanjay Kalra

brideknl@gmail.com

1 Foundation of European Nurses in Diabetes (FEND), London, UK

2 Department of Endocrinology, Bharti Hospital, Kunjpura Road, Karnal 132001, India about diabetes; (3) organise training and teaching in diabetes. It highlighted children with diabetes, gestational diabetes and pregnant women with diabetes as specific focus groups. Numerical targets were agreed upon for prevention of 'costly complications': new blindness due to diabetes (reduction by one third); limb amputations (reduction by one half); and pregnancy outcomes in women with diabetes (similar to those in women without diabetes).

The philosophy of St Vincent was to demand evidence-based treatment and equitable access to care for people living with diabetes, and ask for strong partnerships in diabetes management. Most European governments signed the Declaration and swift action was expected on the ground. However, follow up 10 years later (in Istanbul) and 20 years later (in Glasgow) revealed that much more still needed to be done.

In December 2016, a group of diabetes experts met in Berlin to approve and release the Berlin Declaration [2]. This is a comprehensive document that calls for early action in diabetes to be a political priority status. The Declaration is based upon the findings of four international working groups, which identified four pillars of action. These pillars are prevention, early detection, early control and early access to the right interventions [2].

The document released in Berlin calls for framing of diabetes-focussed policies at national levels, and provides concrete examples of such policies, strategies, targets and monitoring tools. The Berlin Declaration represents a collective ambition to achieve policy change and drive early action in type 2 diabetes.

The Berlin document is co-authored by experts from 11 countries, representing all continents of the globe. It includes partners with a vast footprint, including the International Diabetes Federation, Primary Care Diabetes Europe, Unite for diabetes and the World Heart Federation. It receives 
support from the German diabetes organisation, Deutsche Diabetes Hilfe. This makes Berlin unique in terms of global reach, relevance and respect.

Significant efforts have been made to raise awareness of diabetes, both at an international level with the landmark United Nations (UN) Resolution on diabetes of 2006 [3] and the UN high-level meeting of 2011 and the follow up in 2014. At a European level, the European Parliament Resolution of 2012, the UN Summit on non-communicable diseases (NCDs) 2016 and the 'Diabetes in Europe: Policy Puzzle' report [4] are evidence that diabetes is on the political agenda. However monitoring of implementation of national strategies indicates a lack of progress and sustainability. It is essential that all countries establish a diabetes reference centre and also national diabetes centres as a priority in order to ensure that realistic targets are monitored and re-evaluated.

Nearly three decades later, the Berlin Declaration builds upon and strengthens the legacy of the St Vincent Declaration. The tangible guidance that it provides and the inspirational experience that it shares sets it apart from earlier declarations.

Berlin has been able to create a rubric, with four equally important pillars for early action. Each theme, i.e. prevention, early detection, early control and early access to the right interventions, is discussed in detail. A current situational analysis, future prediction, goals and targets, and strategies to achieve these aims are described [2]. Pragmatic suggestions to make desired policies more likely to succeed are shared, as are best practices from around the world.
The Berlin Declaration thus provides a framework that helps plan both targets for better diabetes care, research and education and the strategies to achieve those targets. The authors highlight that the document is relevant to all nations, regardless of their different health ecosystems and environments. In this way, Berlin echoes the call of St Vincent and takes its philosophy forward across the world.

Duality of interest The authors declare that there is no duality of interest associated with this manuscript.

Contribution statement Both authors were responsible for drafting the article and revising it critically for important intellectual content. Both authors approved the version to be published.

\section{References}

1. (1989) The Saint Vincent Declaration on diabetes care and research in Europe. Acta Diabetologia. 10 (Suppl) 143-144

2. The Berlin Declaration - driving early action in type 2 diabetes (2016). Available at: www.idf.org/berlin-declaration-driving-earlyaction-type-2-diabetes. Accessed 28 Feb 2017

3. United Nations (2007) General Assembly Resolution 61/225. Available at: www.un.org/Docs/journal/asp/ws.asp?m=A/RES/61/ 225. Accessed $21 \mathrm{Feb} 2017$

4. European Coalition for Diabetes (2014) Diabetes in Europe: Policy Puzzle. Available at: www.fend.org/search/node/Diabetes $\% 20$ in $\%$ 20Europe $\% 20 \%$ E2\%80\%93\%20Policy\%20Puzzle. Accessed 21 Feb 2017 